\title{
Risk Assessment of Road Transport in construction Logistic Based on Fuzzy Method
}

\author{
RongZeng ${ }^{a}$, DanniSong ${ }^{b}$ \\ Wuhan University of TechnologyHuaxia College, Wuhan430000, China; \\ asong@163.com, bengr@126.com
}

Keywords:Construction logistics, Risk of road transport, Fuzzy method, Risk assessment

\begin{abstract}
To analysis risk factors of precast beams road transport in Tianjin, expect to promote the safety of road transport in project logistics. For road transport in project logistics, a risk evaluation index system is set up, corresponding data are applied through expert scoring, the analytic hierarchy process are applied to determine the weight of the index system, the fuzzy comprehensive evaluation method is utilized to calculate the risk. The result is that all risks of precast beams road transport in Tianjin are the general risk. The conclusion is that to improve the safety of road transport in project logistics, items focus on improving the items of high weight value, and methods of control the risk are put forward.
\end{abstract}

\section{Introduction}

Risk assessment in the 1960's, many scholars have studied both at home and abroad, has made many achievements. To project logistics risk, foreign logistics enterprises in early to large engineering construction projects, the preparation of material requirements planning,Material purchasing plan, design and implementation of material transportation, loading and unloading, etc. Thus with the large-scale logistics projectThe international operating experience.H. Saidproposed [1] that logistics activities include engineering project Materials procurement and construction process of two main parts, Domestic scholar Dr Weeks straight [2] to the three gorges project for the study of the project as the background, the risk of large project construction implementation stage properties, risk analysis and management models, and in the large engineering project risk identification, risk assessment, risk management have done a lot of problems such as the application of exploratory research. Li Hailing [3], such as the fuzzy comprehensive evaluation in the research on the application of the engineering project risk evaluation is only discussed from the aspects of risk assessment of project logistics risk.

The results of this study has many contents of project logistics risk involved, but not a specific assessment of the risks of road transport system. Taking tianjin precast beam transport of an expressway as example, the transportation risk factor assessment model is established, the comprehensive evaluation of risk, and puts forward the risk evaluation system suitable for the segment precast beam and risk control measures, project logistics for road transportation risk is best services.

\section{Types and Evaluation Method of Risk in Road Transport}

Risk assessment method are many, each method has its own scope of application and shortcomings. In recent years, many scholars of various classical evaluation methods were improved, absorb the advantages of various methods. In order to overcome the traditional risk matrix method of imprecision and uncertainty, Markowski [4] and so on in the risk matrix method to introduce the concept of fuzzy logic. Rezaie [5], etc. Put forward the promotion of monte carlo simulation method, considering the uncertain factors such as time, cost, the connection between.

Aimed at the complexity of the project logistics characteristics, the road transport and complex risk factors, and each factor weight is difficult to define, in this article, through the analytic hierarchy process of risk factors in layered and determine its weight, and then further to evaluate risk by fuzzy theory. 


\section{Evaluation Model of Risk in Road Transport}

Determination of risk factors. Engineering background is the foundation of building model. Here in tianjin a certain section of a highway prefabricated beam transport as an example.

According to the design requirements, $30 \mathrm{~m} * 1.6 \mathrm{~m}$ box girder design the heaviest weight 98.28 $\mathrm{t} ; 35 \mathrm{~m} * 1.8 \mathrm{~m}$ box girder design the heaviest weight $117.18 \mathrm{t} ; 42.5 \mathrm{~m} * 2.2 \mathrm{~m}$ the weight of the heaviest box girder design of $176 \mathrm{t}$. So the blocks the precast beam carried the largest tonnage of 176 tons, the longest 42.5 meters. According to the characteristics of the bridge precast girder transportation and erection, easy to cause the unsafe factors in the construction of the hazards are mainly caused by lifting injuries, equipment damage and casualties caused by electric shock accident. Precast beam transport operations, a section of a highway in tianjin precast beams in the process of road transport, the main risk factors as shown in figure 1:

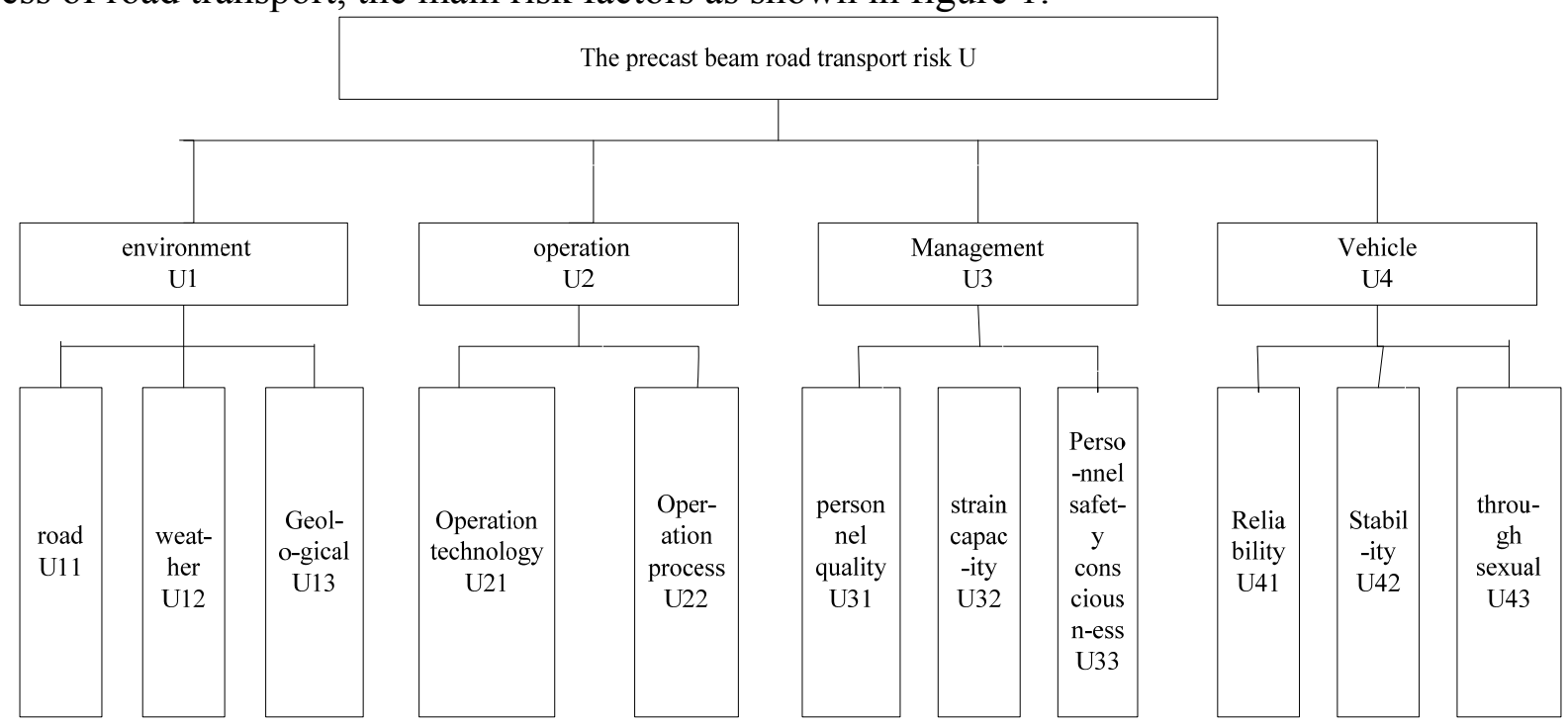

Fig. 1 Hierarchical structure model for road transport risk of precast beam

Analytic hierarchy process (ahp) to determine the weight of risk factors. Hierarchy analysis model is established, the relative importance of each layer factor is given by the expert scoring. For more than two things make accurate comprehensive judgment, is through the evaluation experts, consult SATTY 9 scaling method, defined according to the proportion of scale to the assignment of importance degree, at all levels so as to construct judgment matrix. In order to avoid a lapse in judgment, and to construct judgment matrix and consistency check.

Judgment matrix is used to calculate each index, the consistency of judgement matrix can be accepted, R.I mean random consistency index of them adopt the method of random sampling, its values see table 1 :

Table 1 Average random Consistency Index R.I

\begin{tabular}{c|c|c|c|c|c|c|c|c}
\hline dimension & 1 & 2 & 3 & 4 & 5 & 6 & 7 & 8 \\
\hline $\boldsymbol{R} . \boldsymbol{I}$ & 0.00 & 0.00 & 0.58 & 0.96 & 1.12 & 1.24 & 1.32 & 1.41 \\
\hline
\end{tabular}

Rule layer factors in the environment of target layer, operation, management, vehicle engineering total logistics road transport risk $U$ judgment matrix are shown in table 2 .

Table 2 Judgement Matrix of U-Ui

\begin{tabular}{c|ccccc|c|c}
\hline $\mathrm{U}$ & $\mathrm{U} 1$ & $\mathrm{U} 2$ & $\mathrm{U} 3$ & $\mathrm{U} 4$ & $\mathrm{~W} 0$ & indicators \\
\hline $\mathrm{U} 1$ & 1 & $1 / 3$ & $1 / 5$ & $1 / 3$ & 3 & 0.077 & $\lambda_{\max }=4.104 \quad \mathrm{C} . \mathrm{I}=0.035$ \\
$\mathrm{U} 2$ & & 1 & $1 / 3$ & 2 & 0.238 & R.I $=0.96$ \\
$\mathrm{U} 3$ & 5 & 3 & 1 & 3 & 0.517 & $\mathrm{C} . \mathrm{R}=0.036<0.1$ \\
$\mathrm{U} 4$ & 3 & $1 / 2$ & $1 / 3$ & & 1 & 0.168 & \\
\hline
\end{tabular}


Scheme layer factors $\mathrm{U} 1 \mathrm{j} \mathrm{U} 1$ judgment matrix are shown in table 3.:

\begin{tabular}{c|ccr|c|cc}
\multicolumn{5}{|c}{ Table 3 Judgement Matrix of $\mathrm{U}_{1}-\mathrm{U}_{1 \mathrm{j}}$} \\
\hline$U_{1}$ & \multicolumn{2}{|c}{$U_{11}$} & $U_{12}$ & $W_{1}$ & indicators \\
\hline$U_{11}$ & 1 & $1 / 3$ & $1 / 5$ & 0.106 & $\lambda_{\max }=3.04 \quad$ C.I $=0.02$ \\
$U_{12}$ & 3 & 1 & $1 / 3$ & 0.258 & $R . I=0.58$ \\
$U_{13}$ & 5 & 3 & 1 & 0.636 & C.R $=0.03<0.1$ \\
\hline
\end{tabular}

$\left.W_{l}=(0.106,0.258,0.636), W_{2}=(0.25,0.75), W_{3}=0.106,0.258,0.636\right), W_{4}=(0.090,0.322,0.588) \mathrm{can}$

be calculated, and all the matrix through the consistency check.

Fuzzy comprehensive evaluation. (1) Determining factor set and judgment. Because of project logistics situation is complicated, it is impossible to give accurate estimate even experts, only is a fuzzy evaluation. Language variables can approximately describe complex is not clearly defined the characteristics of the phenomenon. Such as "risk" as the factor set, "high risk, high risk, medium risk and general risk, low risk, no risk" can be set as one of its evaluation. In terms of precast beam transport example, evaluation set $\mathrm{v}=\{$ very high high general low very low $\}$, and carries on the quantification.

Table 4 Quantified Risk Grade

\begin{tabular}{c|c|c|c|c|c}
\hline $\begin{array}{c}\text { risk } \\
\text { level }\end{array}$ & very high & high & general & low & very low \\
\hline $\begin{array}{c}\text { the } \\
\text { value of } \\
\text { index }\end{array}$ & $(8,10)$ & $(6,8)$ & $(4,6)$ & $(2,4)$ & $(2,0)$ \\
\hline
\end{tabular}

(2) Determine the fuzzy relationship matrix and membership degree. Multi-level system of fuzzy comprehensive evaluation started with the lowest layer resulto multi-level comprehensive evaluation, until the highest goal level to get the comprehensive evaluation result of original problem. Here from solution layer index, the first of the magnitude of rule layer fuzzy comprehensive evaluation and fuzzy comprehensive evaluation of target layer factor again.

The second factor fuzzy comprehensive evaluation. The membership $R_{i j}=\left\{r_{i j}, r_{i j 2}, \ldots r_{i j n}\right\}$, the level of single factor evaluation matrix of 2 . Then 2 levels of single factor evaluation matrix as:

$R_{i}=\left[\begin{array}{cccc}r_{i 11} & r_{i 12} & \cdots & r_{i 1 n} \\ r_{i 21} & r_{i 22} & \cdots & r_{i 2 n} \\ & & & \\ r_{i m 1} & r_{i m 2} & \cdots & r_{i m n}\end{array}\right]$ second level fuzzy factors was get. Comprehensive evaluation level $B_{i}{ }^{\prime}=W_{i}$ $\circ R_{i}=\left[b_{i 1}, b_{i 2}, \cdots, b_{i 3}\right], " \circ$ " is the fuzzy operator,can choose the appropriate algorithm according to different situations. Such as the factor set $\mathrm{U} 1=$ \{environment, weather and geological $\}$ the three factors of risk evaluation, assessment team results as shown in table 5.

Table $5 \quad U_{l}$ risk evaluation by Expert

\begin{tabular}{c|c|c|c|c|c}
\hline & very high & high & general & low & very low \\
\hline $\begin{array}{c}U_{11} \\
\text { environment }\end{array}$ & 0 & 0 & 0 & 3 & 7 \\
\hline$U_{12}$ weather & 0 & 0 & 0 & 5 & 5 \\
\hline $\begin{array}{c}U_{13} \\
\text { geological }\end{array}$ & 0 & 0 & 0 & 5 & 5 \\
\hline
\end{tabular}

So $R_{l}=\left[\begin{array}{lllll}0 & 0 & 0 & 0.3 & 0.7 \\ 0 & 0 & 0 & 0.5 & 0.5 \\ 0 & 0 & 0 & 0.5 & 0.5\end{array}\right]$, then $R_{2}=\left[\begin{array}{ccccc}0 & 0 & 0 & 0.9 & 0.1 \\ 0 & 0.6 & 0.4 & 0 & 0\end{array}\right], R_{3}=\left[\begin{array}{ccccc}0 & 0.4 & 0.6 & 0 & 0 \\ 0 & 0.7 & 0.3 & 0 & 0 \\ 0 & 0.2 & 0.8 & 0 & 0\end{array}\right], R_{4}=$ 
$\left[\begin{array}{ccccc}0 & 0.9 & 0.1 & 0 & 0 \\ 0 & 0 & 0.8 & 0.2 & 0 \\ 0 & 0 & 0.5 & 0.5 & 0\end{array}\right]$. Fuzzy operator take the dot product of two matrix, then $B_{l}{ }^{\prime}$
$=(0,0,0,0.48,0.52), B_{2}{ }^{\prime}=(0,0.45,0.30,0.23,0.03), B_{3}^{\prime}=(0,0.35,0.65,0,0), B_{4}=(0,0.08,0.56,0.36,0)$, Always judge matrix is $\mathrm{B}_{\mathrm{i}}$ for the fuzzy matrix, namely

$$
R=\left[\begin{array}{ccccc}
0 & 0 & 0 & 0.48 & 0.52 \\
0 & 0.45 & 0.30 & 0.23 & 0.03 \\
0.26 & 0.35 & 0.62 & 0 & 0 \\
0 & 0.08 & 0.56 & 0.36 & 0
\end{array}\right], \mathrm{so} B=W_{0} \circ R_{i}=(0.15,0.32,0.52,0.15,0.05) \text {. It can be seen from }
$$

the results of the precast beam road transport belongs to general risk. Risk level of evaluation assignment, if $V=(5,4,3,2,1), I_{1}=B_{1}^{\prime} V^{T}=1.48, \mathrm{I}_{2}=3.19, I_{3}=3.35, I_{4}=2.72$, it can be seen that environmental risk lowest, is similar to other risks, belong to general risk. The operation and management of risk should be taken seriously.

\section{Conclusion}

Can be seen from the results, the use of AHP method to determine weights, using expert scoring and fuzzy matrix, finally the conclusion is in line with the actual situation. This method is simple, no complicated theory and mathematical model of risk assessment provides a certain reference value for the future.

Risk factors for this case to build evaluation system is not perfect enough, logistics and engineering has the characteristics of one-off, the point of view is not necessarily suitable for all project logistics road transport risk evaluation, the need to further study.

Membership function in fuzzy theory is important, but there are a lot of method of determining membership functions, this paper USES the method of only one of, each project logistics has its particularity, how to choose the membership function is also need to practice experience.

\section{References}

[1] H. Said, k. El-Rayes:Automation in Construction, Vol. 43 (2014) No.3, p.110-122.

[2] Z.Zhou: Large Project Implementation Stage Risk Analysis and Management Research (Ph.D. Thesis, Tongji University, China,1995).Vol. 1, p.143

[3] H.L. Li,K.J.Liu and Q. Li: Journal of Xihua University (Natural Science Edition), Vol. 11(2005) No.2, p.78-80.

[4] A.S. Markowski and M.S.Mannan: Journal of Hazardous Materials,Vol.11(2008) No.2, p.159-152.

[5] K.Rezaie, M.S.Amalnik and A.Gereie: Applide Mathematics and Computation, Vol. 13 (2007) No.4, p.190-1492. 